\title{
A World to Live In: An Ecologist's Vision for a Plundered Planet
}

\author{
by George M. Woodwell \\ Cambridge, MA: MIT Press, 2016 \\ ISBN 978-0-262-03407-4 \\ Hardcover C\$36.52, 248 pp.
}

Reviewed by Johanne Sanschagrin

Office of the Auditor General of Canada

A World to Live In is a well-crafted book by George M. Woodwell, the renowned ecologist who founded the Woods Hole Research Center (WHRC) in Massachusetts, an institute for global environmental research. Woodwell was among the first scientists to warn us about climate change and its consequences. This book extends that work, by revisiting important cases and sharpening those warnings.

His subtitle leaves no doubt about the threat and its consequences: the planet is being plundered, and at a faster pace than ever. The planet has limits that human organizations-notably in the form of multinational corporations-do not respect, to put it lightly. But Woodwell foresees solutions and he lays them out.

The book has eleven chapters in three parts. Part I depicts the earth as an expansive living system, and then describes how narrow economic perspectives and habits manage human activities in that system to its detriment. Part II dissects the major impediments to redressing the damage. Part III proposes actions to overcome and even redeem the mismanagement of the biosphere.

As Woodwell puts it, there is an inherent and undeniable beauty in the diversity of life on the surface of the planet. It took a very long time for this diversity to develop and reach a natural harmony. But the equilibrium of the biosphere is now threatened by the character and magnitude of human activities. To exploit its natural resources, humanity as a species has assaulted the earth, as if the biosphere was infinitely resilient and as if those resources were not interdependent. But harmony has its limits, and we have overwhelmed them. Woodwell charges that the planet has been relentlessly impoverished, disrupting the equilibrium of the biosphere. Greed-especially organized corporate accumulation-aggressive desires for personal enrichment, and even our reproductive habits are driving these transformations even harder.

In the first part of the book, Woodwell outlines the histories of three large-scale assaults on the resiliency of the planet: the employment of nuclear energy for both industrial energy and militarism, the massive use of DDT (dichlorodiphenyltrichloroethane) for pest control, and the emission of carbon dioxide into the atmosphere. Each of these has been sufficient to change the planet permanently, but taken together, their accumulated effects point to an even bleaker future for human civilization.

In the second part, Woodwell identifies barriers to corrective action. His primary concern is how an unrestrained free market enables moneyed interests to exploit the commons at little or no cost to themselves, an arrangement he calls a "corporate feedlot." Corporate gains and accumulation rely on keeping wages low, and on offloading social, environmental, and economic costs to nations and to society at large. To maintain their economic advantages, international corporations actively resist private countermeasures and government intervention. In many instances, "special interests" have written the laws they operate under. Among their tactics over time: create public doubt as to the validity of scientific data, provide corporate funding to incentivize cooperation at research universities, conceal the real costs of environmental hazards from the public, and self-regulate their own big projects. For Woodwell, unrestrained capital accumulation enables—and even demands - devastating environmental excesses, making the entire planet both setting and victim of the "tragedy of the commons." 
In second place are "right-wing" politics, and governments ruled by a privileged minority. Right-wing politics, mainly in the United States, "drive global political tides," to use Woodwell's astute turn of phrase. He cites Abraham Lincoln's caution about the unacceptability of minority rule in a democracy. Under such regimes, government accommodation of militaristic investments pushes aside civil rights, environmental concerns, human health, and public welfare; public testimonies are suppressed, and science is left to independent organizations.

Woodwell's third class of problems follows from the formulaic myth that humanity can cope with almost anything, and that we will adapt conveniently to climate change. That sort of discourse is offered by interests that serve private profit rather than public welfare, and it fails to address the full costs of "denial" to the world's economies and societies, and to human health and well-being. As a result, we are not developing alternate energies quickly enough, while large zones of the planet are becoming inhospitable and impoverished already.

Finally, Woodwell addresses the belief, or the misplaced faith, that the resources of the planet are unlimited or will regenerate "naturally." Biodiversity is currently declining at a rate never seen before, yet exploiters of fossil fuels, for instance, continue to claim that economic growth can continue indefinitely, and that unspecified sorts of ingenuity can, and will, trump the planet's limits.

In his concluding chapters, Woodwell offers some focused solutions. Though difficult, they are feasible. Human population growth must be brought under control to respect the capacity of the planet, but even a numerically stabilized population is not a solution on its own. Governance of corporate bodies-which enjoy individual rights but operate with very few corresponding obligations - must be transformed. To assign corporations the same accountability that is carried by individuals would entail a paradigm shift. The current, widely held assumption is that corporate profits are shared via taxation to the benefit of a nation, but in practice only the costs of environmental disasters are shared.

We must recognize that the planet is a living system - a collection of living systems — and act accordingly, respecting the full range of life on earth, not merely species by species, but species in their environments as an integral and essential part of the biosphere. Restoring the planet's equilibrium demands immediate attention. Furthermore, we must abandon the exploitation of fossil fuels globally. We must preserve and restore our forests, and impose stringent and careful land use controls. For us to continue to burn fossil fuels and "adapt" to climatic disruption caused by heat-trapping waste gases, now warming the earth, is a ticket to catastrophe. Woodwell argues firmly that we need to implement a closed-cycle approach where all materials are recovered, and reused or remanufactured, at the end of their useful life. None of these are magic, but concerted actions can rebalance the planetary disequilibrium. As the author puts it, we have to come to terms with the fact that civilization is a hazard by definition, and that it is no longer reasonable to assume that the misuse of the planet will be (magically) repaired by the earth's restorative capacities.

Woodwell connects his many dots together well. His overall arguments are strong, and the book is an important contribution to an urgent situation. Some of his examples may seem dated for younger readers, but they come from his own work and experience, and they prove his points, and we are living with their consequences. His is not the only voice, of course, and his particular recommendations, though challenging and debatable, are not far-fetched. Despite his nervousness about politics, this needs to be on political agendas everywhere, lest the evident devastation we and our planet face by inaction gets further out of hand. 